\title{
QUEM DIRIGE A CÂMARA DOS DEPUTADOS? ANÁLISE DO PERFIL SÓCIO-POLÍTICO DOS OCUPANTES DAS CADEIRAS DA MESA DIRETORA DA CÂMARA DOS DEPUTADOS NO BRASIL PÓS REDEMOCRATIZAÇÃO (1987 - 2019)
}

Emanuel Roberto da Silva ${ }^{1}$

\begin{abstract}
Resumo
Nesse projeto de pesquisa busca-se estudar quem são os parlamentares que ocupam as cadeiras da mesa diretora da câmara no Congresso brasileiro, mapeando seu perfil sócio-político por meio de análises prosopográficas. O problema da pesquisa, consequentemente, consiste em verificar quais são as características comuns do grupo designado, identificando correlações que possam ser associadas a um tipo de perfil que consegue ascender politicamente e chegar aos cargos de maior prestígio do Congresso Nacional, os que compõem a mesa diretora. Na pesquisa utiliza-se, para realização dos objetivos, o método prosopográfico, definido pela criação de uma biografia coletiva de um grupo, neste caso os parlamentares ocupantes de posições na mesa diretora da câmara dos deputados, a partir de dados sobre sua trajetória. Tendo como base o texto supracitado, pode-se definir o objetivo desta pesquisa como: Identificar a partir de análise prosopográfica quem são os parlamentares que ascendem ao posto de participantes da mesa diretora da câmara. As informações serão coletadas de três fontes principais, o DHBB (Dicionário Histórico Bibliográfico Brasileiro), o site da câmara dos deputados e o site do TSE (Tribunal Superior Eleitoral). Assim, pelo emprego da análise prosopográfica, é possível constituir relações de sentido com as informações obtidas que possibilitem entender os fenômenos de recrutamento dos integrantes da mesa diretora câmara e como configuram a elite formal do congresso nacional, visto a importância da mesa diretora no andamento do processo decisório da casa legislativa.
\end{abstract}

Palavras-Chave: Recrutamento; Câmara dos Deputados; Prosopografia; Mesa Diretora; Trajetória.

\section{INTRODUÇÃO}

"Few things are as important to a society as how and by whom it is governed (LARSEN, 2015, p. 13). Com isso em mente, buscou-se, neste projeto de pesquisa, estudar quem são e que características são fundamentais para a eleição dos parlamentares que ocupam as cadeiras da mesa diretora da Câmara dos Deputados brasileira, órgão formal de maior importância da Casa. Para isso,

\footnotetext{
${ }^{1}$ Universidade Federal do Paraná, silvaemanuel13@ gmail.com, 0000-0002- 8489-2936
} 
mapeou-se seu perfil sócio-político por meio de análises prosopográficas. O recorte histórico da pesquisa consiste na análise dos ocupantes dessas posições a partir de 1987 até 2019. Este recorte foi escolhido em virtude tanto da ruptura histórica e inauguração de um novo momento na história brasileira que representa, quanto da possibilidade, por ser um período suficientemente longo, de captar um padrão.

À Mesa Diretora da Câmara, compete as funções de direção dos trabalhos legislativos e serviços administrativos da casa, sendo composta por um presidente, dois vice-presidentes, quatro secretários e quatro suplentes. Dotada de grande poder político e capacidade decisória, a Mesa e, consequentemente, os parlamentares que ocupam posições nela, são fundamentais na conformação da política nacional, exercendo sobre ela grande controle, tanto político como administrativo (BRASIL, 1989). Por isso, levando em conta a importância da Mesa Diretora da Câmara dos Deputados para o andamento da política nacional, é de fundamental importância saber quem são os detentores desse tipo de poder no país, visto a influência das características destes indivíduos na qualidade do processo decisório (NORRIS, 2013). Além disso, tão importante quanto, é saber como estes indivíduos “chegam lá”. Para isso foi empregado um estudo do processo de recrutamento, que, em conjunto com a análise do perfil, permite a compreensão das características que são valiosas para uma eleição a um cargo fundamental e, consequentemente, para a constituição de uma elite.

Isto posto, o problema da pesquisa consiste em verificar quais são as características comuns do grupo designado, identificando correlações que possam ser associadas a um tipo de perfil que consegue ascender politicamente em detrimento dos outros candidatos, ou seja, os derrotados no processo. Assim, identificar quem chega e por que chega nos cargos formais de maior prestígio do Congresso nacional.

A pesquisa insere-se no campo da sociologia política, pois utiliza variáveis tanto sociais quanto políticas para explicar o fenômeno de eleição para os cargos da Mesa Diretora em duas frentes: perfil da elite eleita e processo de recrutamento político que resultou na eleição. As duas frentes são fundamentais e complementares, pois a partir delas é que se pode ter uma ideia completa de quem é, de fato, a elite dirigente, evidenciando além de seu próprio perfil, as características e atributos que os diferenciam como elite.

Dessa forma, utilizam-se, para realização dos objetivos, o método posicional para identificação da elite (MILLS, 1981) e o método prosopográfico para realização das análises propostas. O método posicional pressupõe que a elite é composta pelos indivíduos que possuem posições formais de mando (MILLS, 1981) e o método prosopográfico consiste na construção de 
uma biografia coletiva de um grupo, por meio da qual é possível traçar correlações entre elementos de trajetórias individuais que se tornam coerentes para explicação de determinado fenômeno (CODATO, 2015).

O presente trabalho está estruturado em quatro partes: Revisão da literatura, materiais e métodos, resultados e discussão e considerações finais.

\section{REVISÃO DA LITERATURA}

Ao estudar uma elite, como proposto neste trabalho, seja ela de qualquer natureza, parte-se do pressuposto que os autores entendem os atores sociais como peças chave na explicação do funcionamento de fenômenos. Isso implica em um diagnóstico sobre a realidade social que preocupa-se em buscar respostas em outro lugar que não o funcionamento das instituições por si só. Por mais que a importância de constrangimentos institucionais não seja descartada, em estudos de elites ela não é suficiente para alcançar respostas, de modo que devem ser considerados os atributos de sujeitos que detém o poder de tomar decisões.

Devido à proposta e ao modelo deste trabalho, não cabe, na revisão da literatura, uma retomada tão anterior até os estudos dos elitistas clássicos, por mais que a importância de seus escritos sejam fundamentais. Por isso, o ponto de partida da revisão é delegado aos estudos dos três autores que propuseram os principais métodos de identificação de uma elite.

\subsection{COMO IDENTIFICAR ELITES}

"Whether the distribution of power and inequality within a society or the individual behavior of top position-holders in various sectors of society are concerned, the question of how researchers can study elites arises" (SEMENOVA, 2018, p. 71). Tendo isso em vista, é importante visitar as abordagens de três autores que tiveram grande impacto na proposição de metodologias para identificação de elites. São eles Charles Wright Mills, Robert Dahl e Floyd Hunter. Propuseram, respectivamente, o método posicional, o método decisional e o método reputacional para identificar posições de elite.

"Defining and identifying an elite population are the crucial first stage in elite research" (HOFFMANNN-LANGE, 2018, p. 79). Dessa forma, no livro The Power Elite, publicado em 1956, Mills apresenta as bases do método posicional e, consequentemente, sua definição e identificação das elites ao estudá-las nos Estados Unidos. O método proposto pelo autor "enfatiza que os que 
decidem são aqueles indivíduos ou grupos que preenchem posições formais de mando em uma comunidade" (CODATO, 2015, p. 16).

Já o método decisional, proposto por Robert Dahl no livro Who Governs? de 1961, difere-se do posicional por não levar em conta a posição formal dos atores em uma instituição, mas sua participação nos processos decisórios. Codato explica:

O método decisional sustenta, por sua vez, que as pessoas com poder são aquelas capazes de tomar as decisões estratégicas para uma comunidade (ou influenciar as suas decisões mais importantes) e nem sempre se confundem com aquelas que ocupam as posições formalmente designadas como mais relevantes. [Robert Dahl tinha como objetivo] [...] determinar "quem governa" uma comunidade, isto é, entre os vários grupos de pressão e de interesse (incluindo também os políticos profissionais), qual ou quais detêm influência suficiente para estabelecer suas preferências nas decisões públicas (CODATO, 2015, p. 1617).

Por fim, o método reputacional, proposto por Floyd Hunter no livro Community Power Structure de 1953, “[...] relies on experts in order to identify elites” (HOFFMANN-LANGE, 2018, p. 85). Nesse caso, a elite seria um grupo composto por indivíduos que tivessem maior reputação dentro de uma comunidade. Para que o emprego desta metodologia seja possível, formula-se, a partir do método posicional, uma lista de lideranças que compõem as posições formais de mando da comunidade. Esta lista é submetida a especialistas e, com base em suas indicações de quem é mais influente, constitui-se a elite (CODATO, 2015).

Como neste trabalho a identificação da elite estudada será realizada a partir do emprego do método posicional, é pertinente dedicar a ele uma atenção maior a respeito de sua teorização, tendo em vista a clareza metodológica.

\subsubsection{O método posicional}

Wright Mills, no já citado The Power Elites, afirma que "ninguém será, portanto, realmente poderoso a menos que tenha acesso ao comando das principais instituições, pois é sobre esse meios de poder institucionais que os realmente poderosos são, em primeiro lugar, poderosos” (MILLS, 1981, p. 18). Com isso, evidencia a importância da possessão de cargos formais, pois é este o fator que caracteriza a elite e é apenas pela ocupação destes cargos que ela pode existir. As posições formais são chamadas também de "posições estratégicas", pois "controlam 'as principais hierarquias e organizações da sociedade moderna': o aparelho do Estado, as forças armadas e as grandes empresas capitalistas" (CODATO, 2015, p. 20). 
Hoffmann-Lange identifica três passos para que seja possível o emprego do método posicional: Em primeiro lugar, é necessário decidir o número aproximado de membros da elite a ser levado em conta no estudo. Em seguida, decidir sobre quais setores da sociedade serão levados em conta e, por fim, determinar as organizações mais importantes em cada setor estudado (HOFFMANN-LANGE, 2018). Já Codato, de maneira mais detalhada, identifica sete passos fundamentais para estudos que pretendem valer-se do método posicional: 1) determinação das instituições mais importantes, 2) descrição de seus traços principais, 3) evidenciar se existe ou não alguma ligação entre as cúpulas destas instituições, 4) identificação do tipo de recurso social que confere poder ao grupo, 5) definição de que "tipo de pessoa" a elite produz, 6) delimitar o tamanho da elite que realmente manda e, por fim, 7) identificar o tipo de unidade deste grupo (CODATO, 2015).

Com a aplicação do método posicional a este estudo, por meio destes passos, torna-se possível entender porque a Mesa Diretora da câmara dos deputados é uma elite. A seguir isso será evidenciado.

\subsection{MESA DIRETORA, UMA ELITE LEGISLATIVA}

A partir do Regimento Interno da Câmara dos Deputados encontram-se 3 órgãos formais principais: A Mesa Diretora, o Colégio de Líderes e as Comissões Parlamentares (BRASIL, 1989). Destes três, apenas os dois primeiros têm poder decisório. Enquanto à Mesa Diretora "incumbe a direção dos trabalhos legislativos e dos serviços administrativos da Câmara” (BRASIL, 1989), o colégio de líderes representa uma "instância de deliberação parlamentar" (INÁCIO, 2015, 202) e as comissões são divididas em permanentes e temporárias e "têm por finalidade apreciar os assuntos ou proposições submetidos ao seu exame e sobre eles deliberar" (BRASIL, 1989, Art. 22, I).

O objeto desta pesquisa é a Mesa Diretora, por motivos já expostos anteriormente, e são suas atribuições, estrutura e funcionamento que se faz importante salientar, a fim de entender o que faz dela, de fato, uma elite. Nenhum órgão possui tanta concentração de poder formal como a Mesa Diretora, "que comanda os trabalhos legislativos e os serviços administrativos" (ALBUQUERQUE, 2009, p. 32). Eleita a cada dois anos a partir de eleição que segue a regra da proporcionalidade partidária, ou seja, definição de partidos que podem concorrer à eleição ocorre "acordo com o número de cadeiras legislativas que eles ocupam na Casa" (INÁCIO, 2007, 203), porém permitindo também candidaturas avulsas, a Mesa é constituída por um Presidente, dois Vice-Presidentes, $1^{\circ}, 2^{\circ}$, 
$3^{\circ}$ e $4^{\circ}$ secretários. A seleção para candidatos a cada um dos cargos é realizada seguindo o estatuto de cada partido, disposição da bancada ou como dispuser o documento de criação de bloco parlamentar (BRASIL, 1989). Sobre o processo de votação, o regimento interno da Câmara afirma: “votação por escrutínio secreto e pelo sistema eletrônico, exigido maioria absoluta de votos, em primeiro escrutínio, e maioria simples, em segundo escrutínio, presente a maioria absoluta de Deputados" (BRASIL, 1989, Art. $7^{\circ}$ ).

Isto posto, uma Mesa Diretora eleita por estes processos têm as seguintes atribuições principais:

\begin{abstract}
dirigir todos os serviços da Casa durante as sessões legislativas e nos seus interregnos e tomar as providências necessárias à regularidade dos trabalhos legislativos [...], promulgar, juntamente com a Mesa do Senado Federal, emendas à Constituição [...], propor ação de inconstitucionalidade, por iniciativa própria ou a requerimento de Deputado ou Comissão [...], conferir aos seus membros atribuições ou encargos referentes aos serviços legislativos e administrativos da Casa [...], adotar medidas adequadas para promover e valorizar o Poder Legislativo e resguardar o seu conceito perante a Nação [...], declarar a perda do mandato de Deputado [...], propor, privativamente, à Câmara projeto de resolução dispondo sobre sua organização, funcionamento, polícia, regime jurídico do pessoal, criação, transformação ou extinção de cargos, empregos e funções e fixação da respectiva remuneração, observados os parâmetros estabelecidos na lei de diretrizes orçamentárias (BRASIL, 1989, Art. 15)
\end{abstract}

Por mais que possua ainda mais atribuições, as apresentadas acima conseguem representar de forma precisa o poder administrativo e de agenda que o órgão possui. O que se torna mais claro ainda ao olhar individualmente as atribuições de cada posição. Cabe ao Presidente da Câmara, por exemplo,

tomar um conjunto de decisões sobre os trabalhos legislativos, tais como: convocar as sessões da casa; designar a ordem do dia; suspender ou levantar a sessão quando necessário; organizar, ouvido o Colégio dos Líderes, a agenda com a previsão mensal das proposições que serão apreciadas; decidir questões de ordem e reclamações, dentre outras. Durante as sessões deliberativas, compete ao presidente da Mesa conceder a palavra aos deputados, controlar o tempo das intervenções, deferir sobre a retirada de matérias da ordem do dia, despachar requerimentos dos deputados ou líderes e aplicar censura verbal ao deputado. Conseqüentemente, as decisões do presidente da Mesa definem as oportunidades de participação do legislador individual nos trabalhos legislativos, que são, em boa medida, restritas à atuação em Plenário (INÁCIO, 2007, s. n.)

O Presidente é, sem dúvida, o cargo mais importante da Mesa Diretora e mais do que isso, do parlamento como um todo. As funções do Presidente conferem ao parlamentar que ocupa a posição um importante poder sobre as pautas do legislativo, principalmente as atribuições referentes a questões de ordem e ordem do dia, que claramente constituem um poder de agenda incomparável dentro da instituição.

Em relação às atribuições dos vice-presidentes e secretários, Albuquerque explica: 
Aos vice-presidentes incumbe substituir o Presidente em suas ausências ou impedimentos. Os Secretários têm designação de Primeiro, Segundo, Terceiro e Quarto, cabendo ao Primeiro superintender os serviços administrativos da Câmara. As competências de cada Secretário estão definidas em Atos e Portarias internas da Casa, que designam atribuições como o controle de requisição de passagens aéreas, justificativa de faltas de parlamentares, controle sobre os apartamentos funcionais, verbas indenizatórias, dentre outras (ALBUQUERQUE, 2009, p. 35).

Visto isso, assim como referente ao Presidente da Câmara, as regras institucionais aferem aos detentores destes cargos enorme poderio dentro da instituição, seja político, seja administrativo. Caracteriza-se, assim, como uma elite por seguir o princípio fundamental do método de Mills.

Com relação a esta elite, o objetivo deste trabalho é compreender como acontece seu recrutamento, ou seja, quem são os parlamentares que conseguem ascender até ela. Por isso cabem, para finalizar a revisão da teoria, algumas palavras tratando dos fundamentos de estudos sobre recrutamento político.

\subsection{RECRUTAMENTO POLÍTICO}

Em sua maioria, os estudos sobre recrutamento propõem-se a analisar o que Czudnowski chamou de "initial recruitment" (CZUDNOWSKI, 1975, p. 161), ou seja, o recrutamento partidário ou para eleições do legislativo. No caso deste trabalho, será tratado um caso que o autor chama de "political promotion" (CZUDNOWSKI, 1975, p. 161), no qual aborda-se um processo de recrutamento que envolve políticos profissionais e a evolução de suas carreiras.

Isto posto, pode-se definir os estudos de recrutamento como aqueles que preocupam-se com o "processo seletivo de uma elite política” (PERISSINOTTO; MIRÍADE, 2007, p. 2). Dessa forma, diferentemente dos estudos de elites, o processo e os procedimentos, por meio do olhar sobre o desenvolvimento das carreiras políticas, é fundamental nestes casos (CZUDNOWSKI, 1975).

Tendo isso em vista, como alternativa a seguir os estudos de recrutamento partidários, utilizou-se a abordagem que Pipa Norris afirmou que focaliza-se em entender o resultado do processo de seleção (NORRIS, 2013). A autora afirma que "Nessa perspectiva, esses processos são vistos como a variável independente em que, por sua vez, podem lançar luz em quem se torna integrante da elite legislativa e quais conseqüências isso tem para o sistema político como um todo" (NORRIS, 2013, p. 16). Assim, compartilha-se neste trabalho a crença de que "[...] o tipo de candidato nomeado pelos partidos tem a capacidade de influenciar a qualidade dos membros da legislatura e, em última instância, também a composição do governo” (NORRIS, 2013, p. 16). 


\section{MATERIAIS E MÉTODOS}

Em primeiro lugar foi definido o universo da pesquisa, selecionando os parlamentares a partir do método posicional. O método posicional, como já supracitado, "enfatiza que os que decidem são aqueles indivíduos ou grupos que preenchem as posições formais de mando em uma comunidade" (CODATO, 2015, p. 15). Neste caso as posições formais são as cadeiras da Mesa Diretora. Foram elencados todos os parlamentares que ocuparam e que concorreram a estas cadeiras desde 1987, a partir das atas de reuniões da Câmara dos Deputados.

Uma vez explicadas as dinâmicas dos processos de seleção e elencados os parlamentares que participaram dele, a coleta de dados a respeito das características de suas trajetórias foi iniciada, levando em conta informações pessoais, escolaridade e ocupação, carreira, militância partidária, associativismo e atividade legislativa. Além disso, informações a respeito da atividade partidária destes parlamentares também foram coletadas. Estes dados são coletados de modo a abranger diversas variáveis que possam impactar o processo de recrutamento para o órgão analisado, tanto institucionais como individuais.

As informações foram coletadas de três fontes principais, o DHBB (Dicionário Histórico Bibliográfico Brasileiro), o site oficial da Câmara dos Deputados e o site do TSE (Tribunal Superior Eleitoral). Para a coleta de dados, foi utilizado o método prosopográfico, que consiste na "investigação das características comuns de um grupo de atores na história por meio de um estudo coletivo de suas vidas" (STONE, 2011 apud HEINZ;CODATO, 2015, p. 250). Utilizando a prosopografia, após coletar as informações de cada variável sobre os parlamentares em questão, foi possível formular uma biografia coletiva de suas características comuns, que consiste em uma base de dados que permite, ao analisar com minúcia, responder a questão problema desta pesquisa por meio de associações e correlações de informações encontradas, ou seja, "a partir dessa massa de dados, dar um sentido a ela que supere a mera descrição sociográfica do grupo" (HEINZ; CODATO, 2015, p. 270).

Os dados coletados a partir das fontes descritas acima foram agrupados e analisados em programa de análises estatísticas, utilizando tanto frequências simples para a descrição de grupos quanto testes estatísticos mais avançados, como a regressão logística binária2.

\footnotetext{
$\overline{2}$ O mesmo proposto por Perissinotto e Miríade (2009) vale para este trabalho: "A regressão logística é uma ferramenta de análise estatística útil nos casos em que se pretende predizer ou explicar a presença ou ausência de determinada característica a partir dos valores de um conjunto de medidas preditoras. Nesse sentido, é similar aos modelos de regressão linear, porém pode ser aplicado nas situações em que a variável dependente é dicotômica. As variáveis
} 
A partir do emprego da análise prosopográfica, em conjunto com análise empírica do processo de eleição para a mesa e tratamento estatístico, foi possível, a partir das informações obtidas, entender não só o fenômeno de recrutamento político para a Mesa Diretora, como também as dinâmicas que envolvem o universo constituído de relações partidárias, estratégias e características que possibilitam a ascensão de determinados parlamentares a determinadas posições de mando, ou seja, a formação de uma elite parlamentar. Os resultados estão apresentados e discutidos abaixo.

\section{RESULTADOS E DISCUSSÃO}

Após a obtenção dos dados da pesquisa, notou-se que existem diferenças significativas entre o grupo que disputa a presidência da Mesa e o grupo que disputa os demais cargos, bem como entre os eleitos destes grupos, por isso os resultados serão apresentados em três segmentos, primeiramente apresentando as características que podem ser utilizadas para fazer uma caracterização geral do grupo de todos os candidatos à Mesa; em segundo lugar, serão apresentadas as características que diferenciam os candidatos à presidência dos candidatos aos demais cargos; por fim, serão abordadas as diferenças entre eleitos e não eleitos do grupo dos presidentes e do grupo dos demais cargos titulares.

\subsection{CARACTERIZAÇÃO GERAL DOS CANDIDATOS À MESA}

Em primeiro lugar, é de fundamental importância para alcançar os resultados da pesquisa que seja lançado o olhar sobre o processo de recrutamento para a câmara. Segundo o regimento interno da Câmara, no que dispõe sobre a eleição da Mesa:

\footnotetext{
Art. 7o A eleição dos membros da Mesa far-se-á em votação por escrutínio secreto e pelo sistema eletrônico, exigido maioria absoluta de votos, em primeiro escrutínio, e maioria simples, em segundo escrutínio, presente a maioria absoluta dos Deputados, observadas as seguintes exigências e formalidades:

I - registro, perante a Mesa, individualmente ou por chapa, de candidatos previamente escolhidos pelas bancadas dos Partidos ou Blocos Parlamentares aos cargos que, de acordo com o principio da representação proporcional, tenham sido distribuídos a esses Partidos ou Blocos Parlamentares;
} 
[...] Art. 8o Na composição da Mesa será assegurada, tanto quanto possível, a representação proporcional dos Partidos ou Blocos Parlamentares que participem da Câmara, os quais escolherão os respectivos candidatos aos cargos que, de acordo com o mesmo princípio, lhes caiba prover, sem prejuízo de candidaturas avulsas oriundas das mesmas bancadas [...]

[...] § 1o Salvo composição diversa resultante de acordo entre as bancadas, a distribuição dos cargos da Mesa far-se-á por escolha das Lideranças, da maior para a de menor representação, conforme o número de cargos que corresponda a cada uma delas. (BRASIL, 1989)

Os trechos acima destacam os pontos principais no que tange o processo seletivo para a Mesa Diretora. É possível verificar três formas de candidatura: avulsa, pela bancada do partido ou pelo bloco parlamentar. Estas formas de candidatura influenciam o processo devido ao princípio da representação proporcional, que preza a prioridade na escolha dos cargos da Mesa de acordo com o tamanho da bancada.

O processo, entretanto, não ocorre sem controvérsias, sendo as reclamações sobre a distribuição das cadeiras, por parte dos parlamentares, recorrentes. Todavia, por mais que o processo seja, em alguns momentos, controverso, nota-se que no período analisado a regra da proporcionalidade partidária foi seguida com estabilidade: 104 dos 119 parlamentares que ocuparam alguma das 7 cadeiras da Mesa Diretora no período analisado eram políticos dos 7 maiores partidos, $87,4 \%$. O número não chega a $100 \%$ pois fatores previstos no regimento interno preveem a possibilidade da eleição de candidatos avulsos, bem como assegura um lugar na Mesa para a Minoria do parlamento e também dá espaço para a formação de alianças partidárias que podem alterar a distribuição da Mesa por meio da votação e/ou formação de blocos parlamentares.

Independente de possíveis obstáculos, o valor de 87,4\% é expressivo e suficiente para afirmar relativa estabilidade da chamada "tradição" da proporcionalidade partidária. Assim sendo, nota-se que os sete maiores partidos de cada legislatura da Câmara são hegemônicos tanto no número de candidatos à Mesa, quanto no de eleitos: dos 211 parlamentares que participaram do processo para todos os cargos, 181 (85,8\%) eram das bancadas destes. Já os dois maiores partidos, responsáveis pelo maior número de presidentes eleitos (13 dos 17,76,5\%), constitui 37,5\% do total de candidatos, totalizando 79, sendo que destes, 52 (65,8\%) são eleitos, 43,7\% do total geral de 119 parlamentares eleitos para a Mesa. Os números estão presentes na tabela abaixo.

QUADRO 1 - CANDIDATOS DOS MAIORES PARTIDOS ELEITOS PARA A MESA DIRETORA

\begin{tabular}{|c|c|c|c|c|c|c|}
\hline Eleito para a & Membro de & & Membro de & Membro de & Membro de & Total \\
Mesa & um dos sete & & um dos sete & um dos dois & um dos dois \\
maiores & maiores & maiores \\
& maiores & & partidos (em & partidos & partidos (em & \\
\hline
\end{tabular}




\begin{tabular}{|c|c|c|c|c|c|c|}
\hline & & & $\%)$ & & $\%)$ & \\
\hline Não & Não & 15 & 7,1 & 65 & 30,8 & 92 \\
\hline & Sim & 77 & 36,5 & 27 & 12,8 & \\
\hline Sim & Não & 15 & 7,1 & 67 & 31,7 & 119 \\
\hline & Sim & 104 & 49,3 & 52 & 24,7 & \\
\hline Total & 211 & & 100,0 & 211 & 100,0 & 211 \\
\hline
\end{tabular}

FONTE: Câmara dos Deputados (2020)

Os resultados demonstrados a respeito da distribuição partidária da Mesa tornam possível verificar o que poderia ser elencado como o primeiro estágio do recrutamento para este órgão: o processo de seleção é influenciado por variáveis institucionais, de modo que é de extrema importância que o parlamentar que almeja uma posição na Mesa Diretora participe de um dos maiores partidos da câmara, pelo menos um dos sete e, idealmente, um dos dois maiores. Pois estes partidos, respaldados pelo regimento interno, quase monopolizam a ocupação das vagas titulares disponíveis.

Agora, o critério institucional não é único que influencia o processo de recrutamento em questão. Para que seja compreendido em sua completude, é importante também analisar as características individuais dos parlamentares que concorrem aos cargos. Existem características que são definidoras do perfil dos candidatos como um todo. Uma delas, é o estado de nascimento: 163 dos 211 candidatos à Mesa $(77,2 \%)$ são dos estados do nordeste ou do sudeste. Os dados estão presentes na tabela abaixo:

QUADRO 2 - REGIÃO DE NASCIMENTO DOS CANDIDATOS À MESA DIRETORA

\begin{tabular}{|c|c|c|c|}
\hline Grupo & Região de nascimento & & $\begin{array}{c}\text { Região de nascimento (em } \\
\%)\end{array}$ \\
\hline Candidatos à Mesa & Norte & 12 & 5,7 \\
\hline & Nordeste & 82 & 38,9 \\
\hline & Sul & 27 & 12,8 \\
\hline & Sudeste & 81 & 38,4 \\
\hline & Centro Oeste & 9 & 4,2 \\
\hline & Total & 211 & 100,0 \\
\hline
\end{tabular}

Fonte: Dicionário histórico bibliográfico brasileiro (2020)

A predominância das regiões sudeste e nordeste na Mesa Diretora corroboram com os achados de Messenberg (2007), que afirma a grande presença de representantes nordestinos nas Mesas tanto da câmara quanto do senado, contando a partir do pós-constituinte até 2004. A segunda colocação da região sudeste na ocupação dos cargos também é apontada pela autora. 
O grau de escolaridade também é significativo para caracterização do grupo de candidatos, sendo poucos os parlamentares que concorrem à Mesa que não tenham ensino superior, conforme demonstrado abaixo:

QUADRO 3 - NÍVEL DE ESCOLARIDADE DOS CANDIDATOS À MESA DIRETORA

\begin{tabular}{|c|c|c|c|}
\hline Categoria & Nível de escolaridade & $\begin{array}{c}\text { Nível de escolaridade (em } \\
\%)\end{array}$ \\
\hline Candidatos à Mesa & $\begin{array}{c}\text { Menor que superior } \\
\text { completo }\end{array}$ & 29 & 13,7 \\
\hline & Ensino superior completo & 125 & 59,2 \\
\hline & $\begin{array}{c}\text { Maior que superior } \\
\text { completo }\end{array}$ & 55 & 26,0 \\
\hline Total & 209 & & $98,9^{*}$ \\
\hline
\end{tabular}

*2 candidatos não apresentaram informações sobre nível de escolaridade, por isso a porcentagem total não será 100,0\% Fonte: Câmara dos Deputados (2020)

O resultado segue os achados de Mucinhato (2014), que demonstra que desde 1986 até 2012, no mínimo 75\% dos parlamentares de cada legislatura possuíam pelo menos ensino superior completo. Como a presença de bacharéis na câmara é bastante grande, é uma consequência previsível que os candidatos à Mesa também apresentem esse grau de formação.

Outras variáveis que caracterizam todos os candidatos, e podem ser apresentadas juntas, são informações a respeito da rotatividade partidária e participação em órgãos de direção partidária. A rotatividade partidária pode ser definida como a quantidade de partidos pelos quais um parlamentar concorreu a cargos eletivos. Já a participação em órgãos de direção partidária pode ser definida como a participação parlamentar em diretórios ou executivas partidárias de qualquer instância. Segundo Muller (2005), estes fatores podem servir para identificar parlamentares mais "confiáveis" e, no caso da participação em órgãos de direção partidária, permite "verificar o grau de inserção partidária de cada membro" (MULLER, 2005, p. 386). A maioria dos candidatos à Mesa apresentaram rotatividade baixa ( 2 partidos ou menos) e pouco mais da metade deles apresentaram participação em órgãos de direção partidária, conforme mostrado nas tabelas abaixo:

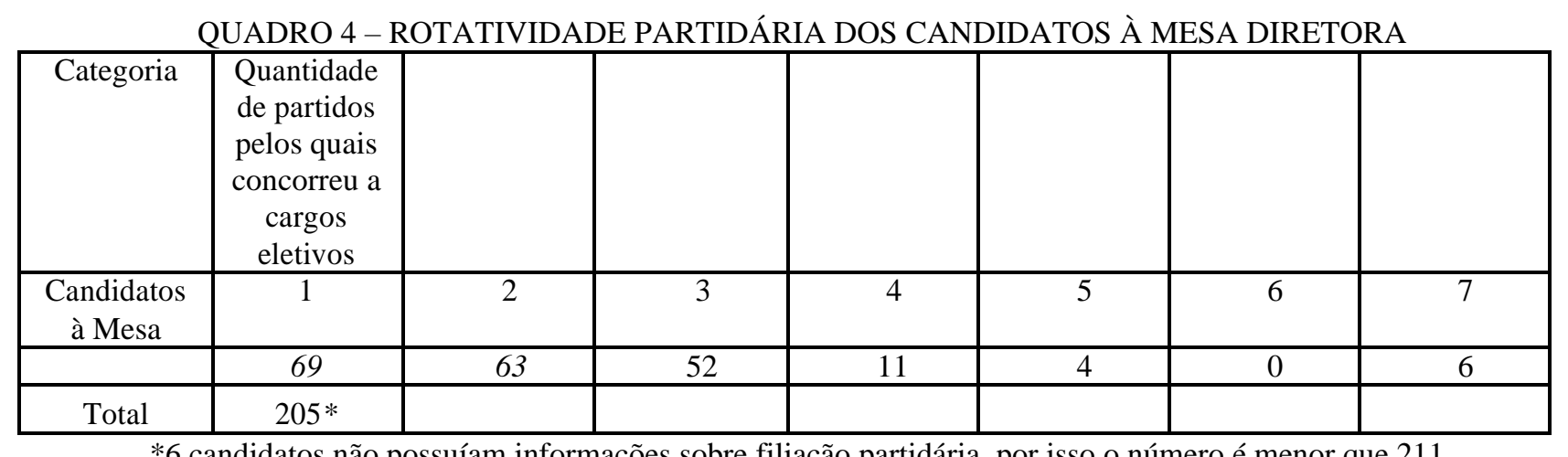


QUADRO 5 - FILIAÇÃO EM ÓRGÃO DE DIREÇÃO PARTIDÁRIA DOS CANDIDATOS À MESA

\begin{tabular}{|c|c|c|c|}
\hline Categoria & $\begin{array}{c}\text { Participou de órgão de } \\
\text { direção partidária }\end{array}$ & $\begin{array}{c}\text { Participou de órgão de } \\
\text { direção partidária (em \%) }\end{array}$ \\
\hline $\begin{array}{c}\text { Candidatos à Mesa } \\
\text { Diretora }\end{array}$ & Não & 105 & 49,8 \\
\hline & Sim & 106 & 50,2 \\
\hline Total & 211 & & 100,0 \\
\hline
\end{tabular}

Fonte: Dicionário Histórico Bibliográfico Brasileiro/Câmara dos Deputados (2020)

\subsection{DIFERENCIAÇÃO ENTRE CANDIDATOS À PRESIDÊNCIA E CANDIDATOS AOS} DEMAIS CARGOS TITULARES

Ao lançar um olhar sobre as características dos parlamentares que concorreram a cargos titulares da Mesa uma coisa fica clara, existem duas classes políticas participando do processo: a) parlamentares com carreiras políticas extensas e que ocuparam cargos importantes em sua carreira legislativa, que disputam os cargos para a presidência da Mesa e b) parlamentares com carreiras políticas menores e pouca participação em cargos importantes, que disputam os outros cargos titulares no geral. Visto essa diferença ao tratar das características dos parlamentares, é importante diferenciar essas duas classes.

Existem 3 fatores que diferenciam os candidatos à presidência dos candidatos aos outros cargos: o fato de ser um parlamentar profissional, a lealdade política e a experiência como líder de bancada partidária ou bloco parlamentar. A razão de chances para cada fator está apresentada no quadro abaixo:

QUADRO 6 - CARACTERÍSTICAS DE DISTINÇÃO DOS CANDIDATOS À PRESIDÊNCIA

\begin{tabular}{|c|c|c|c|}
\hline Categoria & Característica & $\mathrm{B}$ & Odds Ratio \\
\hline $\begin{array}{c}\text { Candidatos à } \\
\text { presidência da Mesa }\end{array}$ & Parlamentar profissional & 1,055 & $2,871^{*}$ \\
\hline & Lealdade política & 0,783 & $2,188^{* *}$ \\
\hline & $\begin{array}{c}\text { Líder de bancada } \\
\text { partidária ou bloco } \\
\text { parlamentar }\end{array}$ & 2,078 & $7,991^{* * *}$ \\
& \multicolumn{3}{|c}{$\mathrm{p}<0,05 / * * \mathrm{p}=0,051 / * * * \mathrm{p}=, 000$} \\
Fonte: O autor $(2020)$
\end{tabular}

A primeira (e uma das mais fundamentais) diferenças entre os dois grupos supracitados é em relação à profissionalização política. A profissionalização política foi aqui definida por um agrupamento das características de extensão e de quantidade de interrupções da carreira política, de modo que quanto mais extensa e com menos interrupções a carreira, mais profissional é o político. 
Todavia, como a carreira política foi definida como a quantidade de mandatos que o parlamentar exerceu na câmara dos deputados, não será chamado de "político profissional" e sim de "parlamentar profissional". Dessa forma, a quantidade de interrupções foi definida como as tentativas mal sucedidas de eleição para a câmara dos deputados.

Separou-se as carreiras políticas em a) curtas, definidas por: quantidade de mandatos que exerceu, na câmara dos deputados, antes da legislatura em que concorreu a cargo na Mesa Diretora igual ou inferior a 2 b) longas, definidas por quantidade de mandatos que exerceu, na câmara dos deputados, antes da legislatura em que concorreu para a Mesa Diretora igual ou superior a 3. Um parlamentar profissional seria o que possui uma carreira longa e nenhuma interrupção entre os mandatos. Visto isso, 30 parlamentares que participaram do processo de seleção para a Mesa tiveram mandatos com interrupções, 11 candidatos à presidência e 19 candidatos aos demais cargos. A partir destes dados foi elaborada uma tipologia com quatro categorias para identificação de parlamentares profissionais:

QUADRO 7 - TIPOLOGIA PARA IDENTIFICAÇÃO DO TIPO DE CARREIRA DOS PARLAMENTARES QUE CONCORRERAM A CARGOS NA MESA DIRETORA

\begin{tabular}{|c|c|c|}
\hline Extensão da Carreira & Intermitência da carreira & \\
\hline & Sem interrupções & Com interrupções \\
\hline Longa & Político profissional & Político intermitente \\
\hline Curta & Neófito & Político ocasional \\
\hline
\end{tabular}

Fonte: $\mathrm{O}$ autor (2020)

Ao verificar o tipo de carreira dos candidatos à Mesa Diretora nota-se que a tendência é que os candidatos que são políticos profissionais concorram ao cargo de presidência. É possível verificar ainda que a tendência é relativamente forte: o fato de ser um parlamentar profissional aumenta em mais de duas vezes a chance do parlamentar ser do grupo de candidatos à presidência. Os resultados encontrados aproximam o perfil dos candidatos à presidência do perfil da elite política brasileira analisada por Messenberg (2007), que afirma que, depois do pós constituinte e até 2004, a "experiência e continuidade na vida legislativa foram, portanto, fatores importantes, embora não indispensáveis, para a formação de um membro da elite do Congresso" (MESSENBERG, 2007, p. 344). Por mais que a análise da autora se estenda apenas até 2004, outros trabalhos também apontam a importância da profissionalização política na formação de uma elite, como Perissinotto e Miríade (2007), por exemplo, que afirmam que a característica de político profissional aumentou fortemente as chances de um candidato ser eleito deputado federal no ano de 2006. Na pesquisa aqui apresentada, corrobora-se o fato de que uma carreira política mais extensa (que, neste caso, foi 
associada a quantidade de interrupções de mandato para criar a categoria de parlamentares profissionais) tende a resultar em maiores chances da inserção do parlamentar em um ambiente associado a elite. Neste caso, quanto maior a profissionalização política, maior as chances do candidato pertencer ao grupo que disputa o cargo de maior importância da Casa Legislativa.

Além disso, outro fator de distinção entre os grupos pode ser a ocupação de posições importantes dentro da Casa, mais especificamente a liderança de bancadas partidárias ou blocos parlamentares. A ocupação de posições formais de mando, na descrição clássica proposta por Mills, apresentada anteriormente, é condição fundamental para a composição da elite, pois podem influenciar no processo decisório. Desse modo, as lideranças partidárias e de bloco são "os portavozes de suas bancadas nas discussões e deliberações em Plenário" (ALBUQUERQUE, 2009, p.

35) e, por isso, juntamente com a presidência da Mesa, são órgãos que centralizam as atividades políticas da câmara (PINTO, 2009 apud ALBUQUERQUE, 2009). Visto isso, dentre os candidatos à Mesa, os que participam dessas importantes posições tem uma grande tendência a serem do grupo que disputa a presidência, conforme já demonstrado no quadro 6.

O fato de o parlamentar ter sido líder de bancada partidária ou de bloco parlamentar aumenta em quase 8 vezes a chance de ele pertencer ao grupo dos candidatos à presidência, um número expressivo. As características apresentadas em relação a este grupo indicam que a disputa pela presidência da câmara é reservada a um número seleto de participantes que possuem características semelhantes ao "alto clero", conforme definido por Messenberg (2010), parlamentares que, dentre outras características, também apresentaram carreira parlamentar longa e a ocupação de cargos chave ${ }_{3}$. Ainda segundo a autora,

A ocupação de cargos-chave na estrutura organizacional da Câmara dos Deputados e do Senado Federal fez parte da trajetória política da grande maioria $(89,4 \%)$ dos membros da elite entre 1989 e 1995 e da totalidade de seus membros nas legislaturas seguintes (MESSENBERG, 2007, p. 333)

A última característica que distingue os candidatos à presidência é a lealdade política. A lealdade política, conforme afirma Muller (2005), leva em conta a rotatividade partidária entre partidos do mesmo espectro ideológico, de modo que "um parlamentar que tenha passado por vários partidos, mas permanecido no mesmo bloco ideológico, pode ser mais 'confiável' do que um

\footnotetext{
${ }_{3}$ Os resultados encontrados não possibilitam, entretanto, defini-los como pertencentes ou não ao alto clero, visto que informações fundamentais sobre a atuação partidária não foram aqui coletadas por não serem interessantes para a pesquisa no momento ou foram coletadas de maneira diferente. O que pode-se afirmar é que algumas características das carreiras políticas dos candidatos à presidência são semelhantes a características dos candidatos definidos como "alto clero" pela autora, um resultado interessante e que possibilita a assimilação destes grupos.
} 
parlamentar que possua uma trajetória de migrações interblocos" (MULLER, 2005, p. 372). Para o trabalho aqui apresentado, seguindo as considerações feitas por Muller, um parlamentar foi definido como tendo lealdade política caso tenha concorrido a cargos eletivos por no máximo dois partidos diferentes, sendo estes da mesma faixa do espectro ideológico4. A lealdade política é fator importante para a indicação de parlamentares a comissões permanentes, por isso vale a pena verificar se o mesmo acontece para a Mesa Diretora. Isto posto, os resultados mostram que um parlamentar que seja um político leal tem pouco mais de duas vezes mais chance de ser do grupo de candidatos a presidência.

Se podemos afirmar que os candidatos a presidência tendem a ser parlamentares profissionais, políticos leais e ocupam cargos chave da câmara, como as lideranças de bancadas partidárias e blocos parlamentares, o inverso é verdadeiro para os candidatos que disputam os demais cargos: tendem a ser políticos intermitentes ou ainda categorias inferiores, bem como também tendem a não ocupar cargos chaves e tem menor possibilidade de serem políticos leais do que os candidatos a presidência. Durante a pesquisa, não foram encontradas outras variáveis que aumentassem a tendência a ser candidato a uma vaga das vice presidências ou secretarias. Assim, faz sentido associar que os políticos que disputam a presidência são os "grandes quadros" do partido, enquanto os "pequenos quadros" disputam as vice presidências e as secretarias.

\subsection{DIFERENCIAÇÃO ENTRE CANDIDATOS ELEITOS E NÃO ELEITOS}

Agora, dentre os candidatos eleitos também existem padrões específicos de recrutamento que diferem entre os grupos. Serão apresentados, primeiramente, os resultados encontrados em relação aos candidatos à presidência da Mesa.

Existem quatro fatores que impactam a eleição dos presidentes da câmara, três impactam positivamente e um negativiamente. Os que impactam positivamente são: ter participado da Mesa Diretora anteriormente, ter sido presidente de comissões permanentes ou relator de comissão parlamentar de inquérito (cpi) e, novamente, ter sido líder de bancada partidária ou bloco

\footnotetext{
${ }^{4}$ Os partidos foram classificados em esquerda, centro e direita, de acordo com a diferenciação feita por Perissinotto e Miríade (2007), de modo que os "partidos de direita - PRB, PP, PTB, PSL, PTN, PSC, PL, PFL, PSDC, PRP, PRONA, PT do B; partidos de centro - PMDB e PSDB; partidos de esquerda - PDT, PT, PSTU, PCB, PPS, PCO, PSB, PV, PSOL, PC do B. Por falta de informação, alguns partidos foram classificados como "indefinidos", sendo este o caso do PAN, PRTB, PHS, PMN e PTC" (PERISSINOTTO; MIRÍADE, 2006, p. 15).
} 
parlamentar. O fator que impacta negativamente é o parlamentar ter participado de seis ou mais comissões parlamentares como membro titular. Os resultados estão presentes no quadro abaixo:

QUADRO 8 - CARACTERÍSTICAS QUE INFLUENCIAM NA ELEIÇÃO DE CANDIDATOS A PRESIDÊNCIA

\begin{tabular}{|c|c|c|c|}
\hline Categoria & Característica & $\mathrm{B}$ & Odds Ratio \\
\hline $\begin{array}{c}\text { Eleitos para a presidência } \\
\text { da Mesa }\end{array}$ & $\begin{array}{c}\text { Participou da Mesa } \\
\text { Diretora anteriormente }\end{array}$ & 2,038 & $7,673^{*}$ \\
\hline & $\begin{array}{l}\text { Presidente de comissões } \\
\text { permanentes ou cpi }\end{array}$ & 3,199 & $24,499 *$ \\
\hline & $\begin{array}{c}\text { Líder de bancada } \\
\text { partidária ou bloco } \\
\text { parlamentar }\end{array}$ & 4,446 & $85,251 *$ \\
\hline & $\begin{array}{c}\text { Membro titular de seis ou } \\
\text { mais comissões }\end{array}$ & $-5,142$ & $0,006^{*}$ \\
\hline & Lealdade política & - & - \\
\hline
\end{tabular}

Fonte: O autor (2020)

Em primeiro lugar, nota-se que a ocupação de cargos importantes na hierarquia da Câmara é novamente um fator importante, agora na distinção dos presidentes eleitos. Neste caso, trata-se do parlamentar já ter sido presidente de comissão parlamentar ou relator de comissão parlamentar de inquérito. Estes cargos possuem, ambos "um poder de agenda das matérias a serem apreciadas em sua câmara" (ALBUQUERQUE, 2009, p. 38), além do adicional dos presidentes de comissão que podem "distribuir o do poder de relatoria dentre os pares" (ALBUQUERQUE, 2009, p. 38-39). Messenberg ainda afirma sobre os cargos que "além de garantir aos seus ocupantes uma série de prerrogativas no processo legislativo, propiciam [...] ampla visibilidade intra e extramuros do Congresso" (MESSENBERG, 2010, p. 100). O valor de 24,499 é significativo, indica que o parlamentar do grupo dos candidatos à presidência que ocupou essas posições durante sua carreira tem mais de 24 vezes mais chances de ser eleito do que um que não ocupou. O grupo de eleitos para a presidência, dessa forma, se aproxima ainda mais do "alto clero" proposto por Messenberg, apresentado anteriormente, visto a quantidade de cargos importantes diferentes ocupados por seus membros.

Ainda outro cargo importante que influencia no processo de eleição é, novamente, o de líder de bancada partidária ou bloco parlamentar. A ocupação desses cargos, como visto anteriormente, é fundamental na distinção entre os grupos de candidatos que concorrem ou não a presidência, mas a razão de chances é ainda maior no que diz respeito às chances de eleição de um parlamentar que possua essas características. Dessa forma, ter sido líder de bancada ou de bloco parlamentar aumenta em mais de 85 vezes a chance de um parlamentar ser eleito para a presidência. 
Outra posição formal, dessa vez a participação anterior na Mesa Diretora, também é impactante no processo de recrutamento, de modo que, como apresentado no quadro 8 , candidatos a presidência que já participaram da Mesa anteriormente (independente do cargo ocupado) possuem uma chance mais de 7 vezes maior de serem (re)eleitos do que candidatos que não participaram.

Não são, no entanto, todos os cargos da câmara que auxiliam na eleição de um candidato a presidência. A participação, como membro titular, em um número alto de comissões permanentes impacta negativamente o processo, como pode-se ver no quadro 8 (Odds Ratio menor que 1 e valor de B negativo). Pode-se supor que, por mais que a participação em comissões pode tanto gerar uma especialização ao candidato em determinado assunto, quanto facilitar o apoio às suas bases eleitorais (MULLER, 2005), ela não permite tanta participação no processo decisório geral e nem gera tanta visibilidade ao parlamentar, dessa forma é mais difícil que se transforme em capital político (ALCÁNTARA-SAEZ, 2017). Por fim, a lealdade política não apresentou resultados estatisticamente significativos.

Em relação aos candidatos que são eleitos para os demais cargos, o único fator que altera suas chances de vitória é a participação prévia na Mesa diretora. As mesmas variáveis do quadro 8 foram testadas e somente a variável Participação anterior na Mesa foi significativa $(\operatorname{sig}=0,05)$, de modo que os valores de B $(1,063)$ e o Odds Ratio $(2,895)$ indicam que os candidatos que possuem essa característica tem quase 3 vezes mais chances de serem (re)eleitos. Entretanto, tirando o fato de possuir uma participação anterior na Mesa, não existe outra característica que possua influência positiva nas chances de eleição dos candidatos as vice presidências e secretarias. Tal fato pode acontecer pois como os cargos são pouco concorridos, isso acaba influenciado o resultado eleitoral devido a ausência de disputa, visto que por vezes existem candidatos únicos aos cargos, o que gera aleatoriedade ao identificar os perfis dos eleitos. No caso dos presidentes, apenas em 2 eleições não houveram concorrentes, devido ao fato do processo ser mais acirrado, determinadas características são exigidas no processo de recrutamento, sendo este menos suscetível a aleatoriedade.

\section{CONSIDERAÇÕES FINAIS}

Ao término da pesquisa, temos informações suficientes para responder a pergunta: como acontece o processo de recrutamento para a Mesa Diretora da câmara dos deputados? Em primeiro lugar, é necessário apontar o fato que ele depende de critérios tanto institucionais (partidários e regimentais), quanto de caráter individual (características pessoais e carreira política) e tem 
diferenças fundamentais entre os candidatos que concorrem à presidência da Mesa e os que concorrem aos demais cargos.

O processo é monopolizado pelos sete maiores partidos da câmara, tanto em relação aos candidatos, quanto em relação aos eleitos. Ainda, dentre estes, os dois maiores partidos são os que mais possuem parlamentares participando do processo. O fato é respaldado pelo regimento interno, a partir da regra de proporcionalidade partidária e pode ser definido como o primeiro filtro do processo de seleção: é quase imprescindível que um parlamentar que deseja ser eleito para a Mesa seja membro de um dos 7 maiores partidos.

Em relação às variáveis de caráter individual, existem tanto as que servem para definir o grupo geral de candidatos e eleitos, quanto as que diferenciam o presidente dos demais cargos. Em relação as que possuem impacto geral, os candidatos à Mesa são caracterizados por ser das regiões nordeste e sudeste, bem como os eleitos. Os candidatos e eleitos tendem também a possuir grau de escolaridade igual ou maior a graduação completa, bem como possuem baixa rotatividade partidária, de 2 partidos ou menos. Ainda, metade dos candidatos e eleitos à Mesa tendem a ter participado em órgão de direção partidária durante a carreira política.

Por mais que essas características possam caracterizar o grupo geral de candidatos, existem outras que distinguem o grupo dos candidatos à presidência: possuem um perfil que os aproxima do alto clero da Casa, constituído de carreiras políticas longas (definida pela quantidade de mandatos exercidos na câmara) e sem interrupções (ou seja, são parlamentares profissionais), além de ocuparem cargos-chave da câmara, como as lideranças de bancadas partidárias ou blocos parlamentares, além de serem políticos leais. O perfil dos presidentes eleitos se assemelha ainda mais ao alto clero, de modo que, além das características que definem o grupo, os presidentes eleitos tem tendência a ocuparem a presidência de comissões permanentes ou relatoria de cpis, cargos na Mesa diretora e uma chance ainda maior de serem líderes de bancada partidária ou bloco parlamentar.

Em relação aos parlamentares que concorrem aos demais cargos, tendem a ter carreiras políticas menores e, consequentemente, um grau de profissionalização política menor. Participam de menos cargos-chave e o único critério que influencia em sua eleição é a participação anterior na Mesa.

Os achados desta pesquisa auxiliam na produção de conhecimento acerca das relações de poder dentro do legislativo brasileiro, sobretudo demonstrando tendências e características da disputa de um dos cargos de maior influência do país: a presidência da câmara dos deputados. Em 
relação aos achados sobre o recrutamento para os demais cargos, coloca novas questões sobre um grupo pouco pesquisado, podendo até ser questionado se eles também fazem parte da elite, ou se o conteúdo que caracteriza a Mesa Diretora como uma elite parlamentar está todo concentrado na presidência. Ainda, esclarece as nuances de um processo de recrutamento político pouco conhecido.

\section{REFERÊNCIAS}

ALBUQUERQUE, Rebeca de S. L. Processo legislativo e tomada de decisões: a elite parlamentar da câmara dos deputados. Brasília, 2009. Disponível em: <bd.camara.gov.br/bd/handle/bdcamara/3686?show=full> Acesso em: 15/09/2019;

ALCÁNTARA-SAEZ, Manuel. La carrera política y el capital político. UAEM, núm. 73, 2017, pp. 187-204

BRASIL. Câmara dos Deputados. Regimento Interno, estabelecido pela Resolução n. 17, de 1989. Disponível em: <www2.camara.leg.br/atividade-legislativa/legislacao/regimento-interno-dacamara-dos-deputados> . Acesso em: 15/09/2019.

CODATO, Adriano N. Metodologias para a identificação de elites: três exemplos clássicos. In: PERISSINOTTO, Renato M.; CODATO, Adriano N. Como estudar elites. Editora UFPR: Curitiba, 2015;

CZUDNOWSKI, Moshe M. Political Recruitment. In: GREENSTEIN, Fred I.; POLSBY, Nelson W. Handbook of political science: Micro Political Theory. Vol. 2. Addison-Wesley Pub. Co.: 1975.

HEINZ, Flávio; CODATO, Adriano N. A prosopografia explicada para cientistas políticos. In: PERISSINOTTO, Renato M.; CODATO, Adriano N. Como estudar elites. Editora UFPR: Curitiba, 2015;

HOFFMANN-LANGE, Ursula. Methods of Elite Identification. In: BEST, Heinrich; Highley, John. The Palgrave Handbook of Political Elites. Macmillan Publishers Ltd: Londres, 2018;

INÁCIO, Maria M. Estrutura e funcionamento da câmara dos deputados. In: MELO, Carlos R. de; SAEZ, Manuel A. A democracia brasileira: Balanço e perspectivas para o século 21. Editora UFMG: Belo horizonte, 2007. p. 199-235;

LARSEN, Anton G. Elites in Denmark: Identifying the Elite. København: Københavns Universitet, 2015. Disponível em: <https://bibliotek.dk/da/work/870970-basis:51820428> Acesso em: 16/09/2019.

MESSENBERG, D. A elite parlamentar brasileira (1989-2004). Sociedade e Estado, Brasília, v. 22, n. 2, p. 331, maio/ago. 2007 
MILLS, Charles W. A elite do poder. Editora Zahar: Rio de Janeiro, 1981.

MUCINHATO, Rafael M. D. O Congresso Nacional, os partidos políticos e o sistema de integridade : representação, participação e controle interinstitucional no Brasil contemporâneo. José Álvaro Moisés (org.). - Rio de Janeiro : Konrad Adenauer Stiftung, 2014.

MULLER, Gustavo. Comissões e Partidos políticos na câmara dos deputados. In: DADOS Revista de Ciências Sociais, Rio de Janeiro, Vol. 48, no 1, 2005, pp. 371 a 394.

PASQUARELLI, Bruno V. L. Formação de coalizões, apoio legislativo e atuação partidária no legislativo brasileiro. $35^{\circ}$ Encontro anual da ANPOCS, 2011.

PERISSINOTTO, Renato M. As Elites Políticas: Questões de teoria e método. Editora Intersaberes. 2012;

PERISSINOTTO, Renato M.; CODATO, Adriano N. Introdução: o desenho da pesquisa. In: PERISSINOTTO, Renato M.; CODATO, Adriano N.; FUKS, Mario; BRAGA, Sérgio S. Quem governa? Um estudo das elites políticas do Paraná. Editora UFPR: Curitiba, 2007;

PERISSINOTTO, Renato M.; MIRÍADE, Ángel. Caminhos para o parlamento: candidatos e eleitos nas eleições para Deputado Federal em 2006. 32 $2^{\circ}$ Encontro Anual da ANPOCS, 2007.

PINTO, Júlio R. de S. Institutos e processos do legislativo brasileiro: uma análise comparada e histórica. $1^{\text {a }}$ ed. Rio de Janeiro: Forense, 2009.

SEMENOVA, Elena. Research Methods for Studying Elites. In: BEST, Heinrich; Highley, John. The Palgrave Handbook of Political Elites. Macmillan Publishers Ltd: Londres, 2018. 